\title{
Article \\ Effectiveness of a Mindfulness-Based Intervention Program for Women Family Caregivers of Older Adults
}

\author{
Cristina Fernández-Portero ${ }^{1}$, David Alarcón ${ }^{1, *}{ }^{\mathbb{C}}$, Ana Gallardo-Flores ${ }^{2}$, Josue G. Amián ${ }^{1}$ and Jose A. Sánchez-Medina ${ }^{1}$ (D) \\ 1 Deparment of Social Antropology, Psychology and Public Health, Pablo de Olavide University, \\ 41013 Sevilla, Spain; cbferpor@upo.es (C.F.-P.); jgarami@upo.es (J.G.A.); jasanamed@upo.es (J.A.S.-M.) \\ 2 Deparment of Social Work and Social Services, Pablo de Olavide University, 41013 Sevilla, Spain; \\ amgalflo@upo.es \\ * Correspondence: dalarub@upo.es; Tel.: +34-95-4977-406
}

Citation: Fernández-Portero, C.; Alarcón, D.; Gallardo-Flores, A.; Amián, J.G.; Sánchez-Medina, J.A. Effectiveness of a Mindfulness-Based Intervention Program for Women Family Caregivers of Older Adults. Healthcare 2021, 9, 1216. https:// doi.org/10.3390/healthcare9091216

Academic Editor: Robbert Gobbens

Received: 25 August 2021

Accepted: 13 September 2021

Published: 15 September 2021

Publisher's Note: MDPI stays neutral with regard to jurisdictional claims in published maps and institutional affiliations.

Copyright: (c) 2021 by the authors. Licensee MDPI, Basel, Switzerland. This article is an open access article distributed under the terms and conditions of the Creative Commons Attribution (CC BY) license (https:// creativecommons.org/licenses/by/ $4.0 /)$.

\begin{abstract}
Background: The objective of this study was to analyze the effectiveness of a mindfulnessbased intervention program for the promotion of well-being and health in family caregivers. Methods: The participants were 111 family women caregivers aged between 33 and 75 years old. This was a double-blinded randomized controlled trial. The mindfulness intervention program lasted 12 weeks. The experimental group underwent mindfulness and acceptance-based interventions (MABIs). The control group performed physical activity training. Results: A cross-lagged panel analysis was computed with the two waves of health, well-being, burden and resilience and age in years and intervention as predictors. The cross-lagged path model fit well $\chi^{2}(8)=7.179, p=0.51$, root mean square error of approximation $($ RMSEA $)=0.00$, comparative fit index $(\mathrm{CFI})=1.00$, standardized root mean square residual $(\mathrm{SRMR})=0.05$. The mindfulness intervention program was a significant predictor accounting for decreasing health problems $(\beta=-0.292, p<0.01)$ and burden $(\beta=-0.190$, $p<0.01)$ and increasing well-being $(\beta=0.107, p<0.05)$ at post-test. Conclusions: Mindfulness-based intervention programs are effective in coping with the burden of family caregivers and, in turn, in promoting resilience, well-being and health among caregivers. Our findings encourage clinical uses of mindfulness interventions to promote health.
\end{abstract}

Keywords: women caregivers; health; resilience; mindfulness; well-being

\section{Introduction}

In recent decades, the number of people over the age of 60 has increased worldwide, representing $8.5 \%$ of the world's population in 2016, 617 million older people [1]. The oldest continent is Europe with more than one-fifth of the population (20.3\%) over 65 . Prospective studies estimate that by 2100 this figure will increase to $31.3 \%$ [2]. In Europe, of the 447 million people in 2020, 49\% (218 million) were men and 51\% (228 million) were women. The dependency rate was expected to reach $82.6 \%$ in 2100 compared to $54.9 \%$ on the European continent in 2019. In this context, Spain is one of the European countries that has aged the most in recent years $[3,4]$.

Of the 46,722,980 people in Spain, $19.1 \%$ are older people, of whom 3,839,711 are men and 5,068,440 are women. Women have a higher life expectancy than men (85.7 vs. 80.4). However, their "healthy" life expectancy is shorter. Healthy life expectancy is calculated based on chronic morbidity and self-perceived health status. This indicates that although women live longer, their health is worse than that of men. In fact, $52.3 \%$ of men perceive their health as good, while only $40 \%$ of women rate their health as good or very good [5].

Given the aging of the population in Spain, the number of people who live alone and who need care has increased drastically in the last decade [5,6]. Seventy-three percent of the population over 65 years of age has difficulties performing daily life tasks due to the appearance of diseases and illness because of the aging process [6]. These health issues require care that most of the aging population prefers to receive at home [7]. The number 
of family caregivers has increased, representing $80 \%$ of the total care received by older adults [6].

Family care tasks tend to fall more frequently on women than men as part of their family and social role [8,9]. In fact, $75 \%$ of family caregivers of people with disabilities and $60 \%$ of caregivers of older adults in Spain are women $[10,11]$. The profile of family caregivers in Spain is between 45 and 65 years old; they dedicate more than $20 \mathrm{~h}$ a week to care tasks and tend to have emotional ties with the people receiving care [5]. Family care comes mainly from daughters who take care of their parents, followed by other relatives and/or friends. Therefore, it is necessary to study the possible consequences of family care tasks on the health and well-being of female caregivers.

Women caregivers have poorer well-being than those who do not perform caregiving tasks for their elders [12]. This deterioration in well-being among family caregivers is frequently associated with suffering from other health problems [13]. A meta-analysis found that high levels of stress and depression in female caregivers were associated with low levels of well-being [12]. Another study with 125 family caregivers, found a relationship between high levels of depression and anxiety and care tasks [13]. Other authors highlight depressive symptoms, anxiety, and sleep problems among the most common health disorders in female caregivers [14]. These authors defend the need to promote resources that increase the well-being of family caregivers and the quality of life of patients. The negative effects on the health of female caregivers are significantly maintained over time after a period of 8 years [15]. Identifying risk and protective factors that influence health and well-being in caregivers can help to prevent these negative effects.

The perception of burden can be a risk factor for the health and well-being of family caregivers [16-18]. Burden is defined as the caregiver's perception of the impact that care tasks have on their health and on their social, personal, and economic life [19]. Family care increases the quality of life of older adults due to its continuity in their social environment. However, the health and well-being of the caregiver can be affected by the perception of burden, isolating him or her and occupying all his or her free time [20]. Good physical and mental training is necessary to cope with the tensions that the caregivers' burden generates [21].

In contrast, resilience is a protection factor against caregiver burden [22,23]. Resilience is defined as the ability to overcome adversity, recover and strengthen after exposure to a traumatic psychosocial event, and is considered a coping strategy [24-26]. Family caregivers who have low resilience experience a higher burden when faced with the demands of the caregiver, while family caregivers with high levels of resilience experience a lower burden due to the high demand for care [27]. Therefore, promoting the resilience of family caregivers can promote their health and well-being [28].

Recent studies show the effectiveness of mindfulness-based techniques in family caregivers [29-31]. A meta-analysis review concluded that mindfulness techniques are being imposed on interventions based on psychosocial, psychoeducational and counseling programs [31]. To date, only small effects of cognitive-behavioral therapy (CBT) have been shown in depression and family caregiver burden. However, interventions based on mindfulness techniques (mindfulness and acceptance-based interventions-MABIs) show significant effects on the reduction of depression and the burden of family caregivers [31]. There are different types of mindfulness-based interventions, such as interventions focused on stress reduction (MBSR), mindfulness-based cognitive therapies (MBCT), acceptance and commitment therapies (ACT) or dialectical-behavioral therapy (DBT). All of them focus on mindfulness but differ in the duration and practice of meditation and the way teaching behavior changes strategies. The study concludes that, in general, mindfulnessbased intervention programs have a large effect in reducing the levels of depression in family caregivers and a moderate effect in reducing burden. However, as it is a novel field of intervention, it is necessary to continue investigating its effects on health and the burden of family caregivers [31]. 
The objective of this research is to analyze the effectiveness of a mindfulness-based intervention program for the promotion of well-being and health among female family caregivers. We hypothesize that the women caregivers who participated in the mindfulness intervention program would show a decrease in their perceived burden and an increase in their resilience, while the mindfulness intervention program would enhance their health and well-being.

\section{Materials and Methods}

\subsection{Participants}

The participants of the present study were 111 women aged between 33 and 75 years old (mean $=52.08$ and SD =9.34). All of them were family women caregivers who spent at least eight hours a day caring for a family member either in the caregiver's own home or in the older adults dependent's home. Significant differences by age were observed between the control group (CG) and experimental group (EG), $t=2.251, p<0.05$. Hence, to control for these differences between groups, age in years has been used as a covariate variable in the remaining analysis. No differences were observed between the groups by educational level $\left(\chi^{2}=2.523, p>0.05\right)$, and most of the family caregivers had completed only primary education. Regarding whether they lived alone or accompanied, 97.7\% lived in the company of other people, and no differences were observed between the control and experimental groups $\left(\chi^{2}=0.486, p>0.05\right)$.

\subsection{Instruments}

The instruments for data collection were the Satisfaction with Life Scale, the Goldberg Health Questionnaire, the Connor-Davidson Resilience Scale and the Zarit Caregiver Burden Interview. The self-reported measures were collected at pre-test (Time 1, T1) and post-test (Time 2, T2).

The Satisfaction with Life Scale (SWLS) [32] measures the well-being of people with their lives. It is a Likert scale with seven Likert-type response options ranging from 1 (Strongly disagree) to 7 (Strongly agree) to higher scores higher well-being. The reliability of the scale was high in T1 $(\alpha=0.873)$ and T2 $(\alpha=0.858)$.

The Goldberg Health Questionnaire (GHQ-12) [33] measures psychological distress and detects changes in the psychological functioning of the person. The abbreviated version of 12 items was selected for this study with Likert-type response options ranging from 1 to 4 ; the more positive the response is, the more it tends to 1 . The reliability of the scale was high in T1 $(\alpha=0.855)$ and T2 $(\alpha=0.863)$.

The Connor-Davidson Resilience Scale (CD-RISC) [34] measures resilience on a scale of 25 items on a scale of $0-4$, where $0=$ "has not been true at all" and $4=$ "true almost forever". The total scores range between 0 and 100; higher scores indicate greater resilience. The reliability of the scale was high at T1, with a Cronbach's $\alpha$ of 0.905 , and T2 $(\alpha=0.905)$.

The Zarit Caregiver Burden Interview (ZBI) [35] measures the degree of burden of caregivers on a 22-item Likert-type scale with response options ranging from 1 (never) to 5 (almost always). The response is more positive and implies less burden the more it tends to 1 . The scale had a high reliability in T1 $(\alpha=0.909)$ and T2 $(\alpha=0.907)$.

\subsection{Procedure}

This is a double-blinded randomized controlled trial. Family women caregivers were recruited while attending a call by the town hall to participate in a formative course. The inclusion criterion was a woman taking care of a family member over 60 years old. The number of participants was 121, but only 117 met the inclusion criteria for eligibility (four participants were men). The participants were included in the experimental or control group by random number generation by researchers not involved in the enrollment of participants, see Figure 1. 


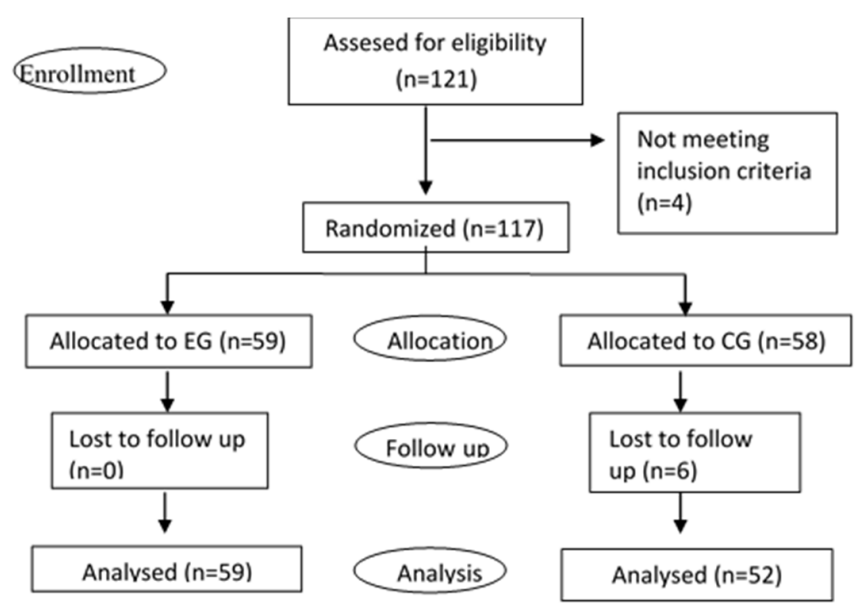

Figure 1. Consort diagram. Note: EG, experimental group; CG, control group.

The experimental and control intervention programs lasted 12 weeks, with one session per week. Data were collected the first week before the intervention program (pre-test) and the week after the program (post-test). All participants began the intervention programs at the same time in small groups of 15 participants.

The experimental group underwent mindfulness and acceptance-based interventions (MABIs) among all the sessions, and the exercises focused on mindfulness practices and attempted to raise present awareness and acceptance, combined with yoga, breathing relaxation and meditation based on similar studies [36-38]. In each session, there was a particular meditation objective with a combination of mindfulness and acceptance exercises, as described in Table 1. In the mindfulness and acceptance-based intervention program, all the techniques were used with the aim of deepening awareness, self-compassion, and selfknowledge. In the final session, working groups held among the participants to evaluate the knowledge acquired during the intervention and to analyze the applications in their daily life. The structure of each MABI training session was: (1) check-in and reflecting on personal practice of previous week working activity for $10 \mathrm{~min}$, (2) explaining and practicing new exercise and meditation for $40 \mathrm{~min}$, and (3) debriefing the meditation experience for $10 \mathrm{~min}$. The trainer of the EG was an expert in mindfulness.

Table 1. Mindfulness and acceptance-based intervention program sessions.

\begin{tabular}{ll}
\hline \multicolumn{1}{c}{ Sessions } & \multicolumn{1}{c}{ Objective } \\
\hline S1: Raisin Exercise & Focus on the present \\
\hline S2: Body Scan & Focus on the body \\
\hline S3: Mindful Movement & Centering the mind through the body movements \\
\hline $\begin{array}{l}\text { S4: Mindfulness of the breath, } \\
\text { sounds, and thoughts }\end{array}$ & Combining breathing and displacement in space \\
\hline $\begin{array}{l}\text { S5: Acceptance of thoughts and } \\
\text { feelings exercise }\end{array}$ & Learning to know yourself \\
\hline S6: Mindful Seeing & Encourage contact with the environment \\
\hline S7: Lake meditation & Self-compassion and acceptance and taking care of yourself \\
\hline S8: Acceptance of Social Anxiety & Connecting self-knowledge with relationships with others \\
\hline S9: Lovingkindness Meditation & Compassion and acceptance to the others \\
\hline S10: Mountain Meditation & Raising self-esteem \\
\hline S11: Turning Toward Meditation & Dealing with difficult emotions and/or physical pain \\
\hline S12: Silent meditation & $\begin{array}{l}\text { Evaluation of acquired knowledge and application to daily } \\
\text { life }\end{array}$ \\
\hline
\end{tabular}


On the other hand, the CG performed physical activity training under an expert trainer during the 12 weeks of the mindfulness intervention program. The structure of each physical training session was: (1) warming ups for $10 \mathrm{~min},(2)$ endurance and resistance exercises for $40 \mathrm{~min}$, and (3) stretching exercises for $10 \mathrm{~min}$. The trainer of the CG was an expert in physical training.

\subsection{Data Analysis}

Statistical analyses were performed using SPSS version 23, employing a statistical significance at $\alpha=0.05$. Descriptive analyses were used to describe the sample characteristics (i.e., sociodemographic). Repeated-measures ANOVA F-tests were used to assess time differences by intervention group. Pearson correlation analyses were performed to evaluate scales measures associations. A cross-lagged panel analysis was computed to examine associations between pre and post intervention changes in the psychological variables employing Mplus version 8 [39].

\subsection{Ethical Considerations}

The study was conducted according to the guidelines of the Declaration of Helsinki, Voluntary informed consent was requested. Participants were informed about the aims of the research and the right to withdraw without penalty if they wished. Questionnaires were registered with strict confidentiality.

\section{Results}

To assess the effects of the mindfulness intervention program, a repeated-measures ANOVA was performed by time (T1 and T2) and group (EG and CG) with age in years as a covariate (see Table 2). There were non-significant differences between the experimental and control groups at T1 on any of the dependent variables: health, well-being, resilience, and burden. Thus, the experimental and control groups were equivalent on the dependent measures at the pre-test.

Table 2. Descriptive analysis of health, well-being, resilience, burden and resilience in Time 1 and Time 2 by experimental group (EG) and control group (CG).

\begin{tabular}{|c|c|c|c|c|c|c|c|}
\hline & \multicolumn{2}{|c|}{ Pre-Test (T1) } & \multicolumn{2}{|c|}{ Post-Test (T2) } & \multirow{3}{*}{$\mathbf{F}$} & \multirow{3}{*}{$p$} & \multirow{3}{*}{ Eta } \\
\hline & EG $(n=59)$ & CG $(n=52)$ & EG $(n=59)$ & CG $(n=52)$ & & & \\
\hline & \multicolumn{2}{|c|}{ Mean (SD) } & \multicolumn{2}{|c|}{ Mean (SD) } & & & \\
\hline Health & $2.21(0.52)$ & $2.06(0.47)$ & $1.94(0.45)$ & $2.12(0.48)$ & 27.849 & 0.000 & 0.204 \\
\hline Well-being & $3.48(0.98)$ & 3.85 (1.07) & $3.70(0.94)$ & 3.85 (1.07) & 4.716 & 0.032 & 0.041 \\
\hline Burden & $2.33(0.64)$ & $2.25(0.68)$ & $2.22(0.63)$ & $2.34(0.66)$ & 9.469 & 0.003 & 0.080 \\
\hline Resilience & $3.65(0.56)$ & $3.79(0.64)$ & $3.70(0.54)$ & $3.56(0.78)$ & 6.599 & 0.012 & 0.057 \\
\hline
\end{tabular}

Note: F report interaction effect on health and psychological measures.

However, there were significant interaction effects between time and group on the psychological measures when considering the change between T1 and T2. There was a significant interaction effect between time and group on the health measure, F (1109) $=27.849$, $p=0.000, \eta p^{2}=0.204$. Bonferroni-adjusted post hoc tests revealed that the participant's health improved significantly between T1 and T2 in the experimental group $(p<0.001)$, whereas there were non-significant differences in the control group $(p=0.148)$. There was a significant interaction effect between time and group on the well-being measure, $\mathrm{F}(1109)=4.716, p=0.032, \eta \mathrm{p}^{2}=0.041$. The differences by group and time show that wellbeing increased significantly in the EG $(p=0.001)$, but there were non-significant differences by time in the CG $(p=0.707)$. The interaction effect of time and group on burden was statistically significant, $\mathrm{F}(1109)=9.469, p<0.003, \eta p^{2}=0.080$. The differences show that the burden level decreased in the EG $(p=0.003)$ and increased in the CG $(p=0.019)$. There was a significant interaction effect of time and group on the resilience measure, $F(1109)=6.599$, 
$p=0.012, \eta p^{2}=0.057$. The differences by group and time showed that resilience decreased significantly in the CG $(p=0.01)$, but there were non-significant differences by time in the EG $(p=0.568)$. In summary, a significant intervention program effect was observed in the psychological measures of the EG, improving their health, well-being, and burden, whereas a decrease in resilience was observed in the CG over time.

A Pearson correlation analysis showed that there were no significant correlations between the age of the participants and the psychological variables observed at T1 and T2, see Table 3. The participant's health problems were negatively correlated with well-being at T1 and at T2. Problems of health and burden were positively correlated at T1 and at T2. Problems of health were also negatively correlated with resilience at T1 and at T2. Well-being was negatively correlated with burden at T1 and burden at T2. Well-being was positively correlated with resilience at $\mathrm{T} 1$ and at $\mathrm{T} 2$. Burden was negatively correlated with resilience at T1 and at T2 $(r=-0.248, p<0.001)$. Table 4 shows high significant positive correlations within measures between $\mathrm{T} 1$ and $\mathrm{T} 2$.

Table 3. Analysis of correlations between age, health, well-being, overload and resilience in pre-test (T1) and post-test (T2).

\begin{tabular}{llllll}
\hline & $\mathbf{1}$ & $\mathbf{2}$ & $\mathbf{3}$ & $\mathbf{4}$ & $\mathbf{5}$ \\
\hline 1. Age & 1 & 0.127 & 0.052 & 0.001 & -0.189 \\
2. Health & 0.086 & 1 & $-0.451^{* *}$ & $0.454^{* *}$ & $-0.277^{* *}$ \\
3. Well-being & -0.050 & $-0.428^{* *}$ & 1 & $-0.215^{*}$ & $0.260^{* *}$ \\
4. Burden & 0.077 & $0.504^{* *}$ & $-0.336^{* *}$ & 1 & $-0.249^{*}$ \\
5. Resilience & -0.038 & $-0.451^{* *}$ & $0.321^{* *}$ & $-0.280^{* *}$ & 1 \\
\hline
\end{tabular}

Note: Time 1 correlations are in the lower part and the Time 2 correlations are in the upper right part. ${ }^{* *}$ Correlation is significant at level $0.01 ;{ }^{*}$ Correlation is significant at level 0.05 .

Table 4. Analysis of correlations between age, health, well-being, overload and resilience between pre-test (T1) and post-test (T2).

\begin{tabular}{lcccc}
\hline & Health T2 & Well-Being T2 & Burden T2 & Resilience T2 \\
\hline Health T1 & $0.612^{* *}$ & $-0.372^{* *}$ & $0.444^{* *}$ & $-0.338^{* *}$ \\
Well-being T1 & $-0.300^{* *}$ & $0.823^{* *}$ & $-0.319^{* *}$ & $0.260^{* *}$ \\
Burden T1 & $0.409^{* *}$ & $-0.277^{* *}$ & $0.857^{* *}$ & $-0.248^{*}$ \\
Resilience T1 & $-0.268^{* *}$ & $0.317^{* *}$ & $-0.227^{*}$ & $0.767^{* *}$ \\
\hline
\end{tabular}

** Correlation is significant at level $0.01 ;{ }^{*}$ Correlation is significant at level 0.05 .

To explain the relationships in time between the psychological variables, a crosslagged panel analysis was computed with the two waves of the four measures and age in years and intervention as predictors. The cross-lagged path model fit well $\chi^{2}(8)=7.179$, $p=0.51, \mathrm{RMSEA}=0.00, \mathrm{CFI}=1.00, \mathrm{SRMR}=0.05$. Figure 2 shows the cross-lagged model with the correlations between the variables at $\mathrm{T} 1$ and $\mathrm{T} 2$ and the percentage of explained variance of each of the variables at $\mathrm{T} 2$. The model explains $63 \%$ of the variance in health problems at $\mathrm{T} 2,75 \%$ of the explained variance in well-being at $\mathrm{T} 2,76 \%$ of the explained variance in burden at $\mathrm{T} 2$ and $38 \%$ of the explained variance in resilience at T2.

As expected, see Table 5, we found evidence for longitudinal associations between the autoregressive paths from T1 to T2; thus, the baseline measure at pre-test was a significant predictor of the post-test score of the same measure ( $\beta=0.604$ to 0.838$)$. Likewise, for each measure, higher scores at T1 predicted higher scores at T2. The cross-lagged paths between different measures were non-significant $(p>0.05)$. Controlling for the baseline at T1, age in years was a significant predictor for wellbeing at T2 $(\beta=0.097)$ and burden at T2 $(\beta=0.147)$. Older family caregivers were likely to increase their post-test wellbeing and decrease their post-test burden. Furthermore, when controlling for the baseline at $\mathrm{T} 1$ and age, the mindfulness intervention program was a significant predictor accounting for decreasing health problems at T2 $(\beta=-0.292, p<0.01)$, increasing well-being at T2 $(\beta=0.107, p<0.05)$, and decreasing burden $(\beta=-0.190, p<0.01)$. However, the 
intervention group was marginally significant in increasing resilience at T2 $(\beta=0.147$, $p=0.051)$.

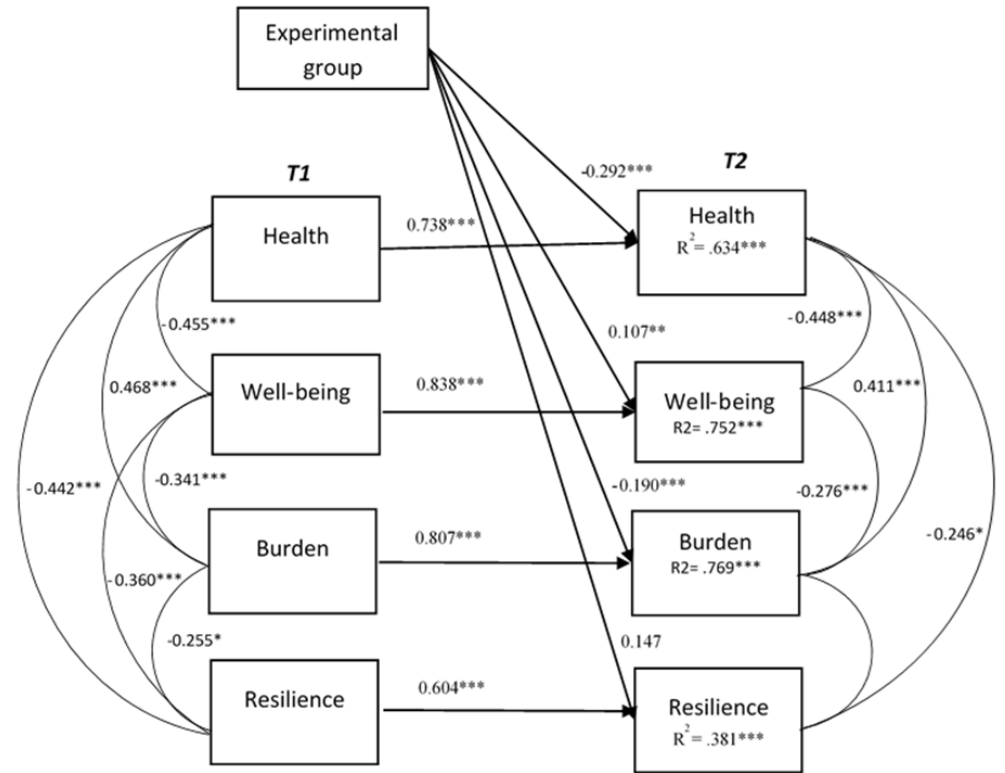

Figure 2. Cross-lagged relationships between health, well-being, burden and resilience at pre-test (T1) and post-test (T2). Model fit: $\chi^{2}(8)=7.179, p=0.51$, RMSEA $=0.00, \mathrm{CFI}=1.00, \mathrm{SRMR}=0.05$. * Correlation is significant at level 0.05 ; ${ }^{* *}$ Correlation is significant at level 0.01 ; ${ }^{* *}$ Correlation is significant at level 0.001 .

Table 5. Directional path in the longitudinal panel model to examine associations between pre-test (T1) and post-test (T2) measures.

\begin{tabular}{|c|c|c|c|c|c|c|c|c|c|c|c|c|}
\hline & \multicolumn{12}{|c|}{ Dependent Variables } \\
\hline & \multicolumn{3}{|c|}{ Health T2 } & \multicolumn{3}{|c|}{ Well-Being T2 } & \multicolumn{3}{|c|}{ Burden T2 } & \multicolumn{3}{|c|}{ Resilience T2 } \\
\hline & $\mathbf{b}$ & SE & $\beta$ & $\mathbf{b}$ & SE & $\beta$ & $\mathbf{b}$ & SE & $\beta$ & $\mathbf{b}$ & SE & $\beta$ \\
\hline Age & 0.001 & 0.003 & 0.015 & 0.011 & 0.005 & $0.097 * *$ & 0.011 & 0.004 & $-0.147^{* *}$ & -0.008 & 0.007 & -0.112 \\
\hline EG & -0.286 & 0.055 & $-0.292 * * *$ & 0.218 & 0.094 & $0.107 * *$ & 0.254 & 0.065 & $-0.190 * * *$ & 0.198 & 0.106 & 0.147 \\
\hline Health T1 & 0.721 & 0.073 & $0.738 * * *$ & 0.004 & 0.117 & 0.002 & 0.118 & 0.108 & 0.088 & 0.114 & 0.120 & 0.085 \\
\hline Well-being T1 & 0.000 & 0.031 & -0.001 & 0.826 & 0.067 & $0.838^{* * *}$ & -0.008 & 0.036 & -0.013 & 0.032 & 0.050 & 0.049 \\
\hline Burden T1 & -0.013 & 0.045 & -0.017 & 0.012 & 0.083 & 0.008 & 0.813 & 0.057 & $0.807^{* * *}$ & 0.027 & 0.094 & 0.026 \\
\hline Resilience T1 & -0.015 & 0.056 & -0.019 & 0.100 & 0.084 & 0.059 & 0.024 & 0.054 & 0.022 & 0.672 & 0.110 & $0.604 * * *$ \\
\hline
\end{tabular}

Note: EG, Experimental group. * Significant at level 0.05; ** Significant at level 0.01; ${ }^{* * *}$ Significant at level 0.001.

\section{Discussion}

The increase in the older population living at home has implied an increase in the need for family caregivers to help them in their daily activities [5]. In Spain, this task of family care of older adults is usually performed by women; however, performing these daily care tasks often leads to health-related consequences among the family caregivers. In this study, the main objective was to analyze the effectiveness of a mindfulness-based intervention program for the promotion of well-being and health among female family caregivers. The results indicated a significant effect of the mindfulness intervention program in improving health and well-being and reducing burden. The enhancement of the family caregiver's well-being in the experimental group indicated that the mindfulness (MABIs)-based intervention program helped caregivers face care tasks, reducing health problems [40].

Our data support other findings who found that health problems are associated with low levels of well-being in family caregivers [13]. The increased well-being of family caregivers after the mindfulness intervention program indicates that mindfulness-based 
techniques promote the development of strategies and resources to cope with the negative effects of care tasks on their well-being and, in turn, on their health.

The effectiveness of the mindfulness-based intervention program was also observed in reducing the perception of burden in the experimental group [31]. Our data support this statement by observing a decrease in the burden of family caregivers between T1 and T2. The perception of burden could affect the perception of health and well-being of family caregivers [20]. Our data support this finding: there was a positive correlation between health problems and burden; that is, as the burden increased, the caregivers presented more health problems. Therefore, the mindfulness intervention program of our study supports the idea that good physical and mental preparation is needed to manage the burden and improve the well-being of caregivers [21].

However, in our study, the mindfulness intervention program did not significantly increase the resilience in the EG between T1 and T2. There was a significant decline in caregiver resilience in the CG. The mindfulness intervention program could help family caregivers rehearse their resilience [28]. Our results show that resilience promotes the health and well-being of family caregivers.

The cross-lagged analyses show that after controlling for age and the baseline measures, the mindfulness-based intervention program enhanced the health, well-being and burden of family caregivers while protecting the decline in their resilience. As previous meta-analyses show, mindfulness intervention techniques are an effective, useful, and reliable resource to improve the health and well-being of family caregivers [31]. Furthermore, daily mindfulness practices have positive effects on the well-being and health of family caregivers in the long term [38].

Among the limitations of our study was the two-point pre-post experimental design, and more previous and follow-up observation times should be included to account for the long-term effects of the mindfulness intervention on the health and well-being of family caregivers [41,42]. A further limitation of the current study is that the differential effect of a mindfulness intervention program and a physical training program was analyzed. Although previous studies have shown the psychological benefits of physical training in caregivers [43,44]; in the present study non-significant effects of the physical training program were observed in the control group. This may be because only a 1-hour session per week of physical training was performed while in the experimental group in addition to the weekly mindfulness session; and participants were encouraged to perform at home the activity practiced in weekly mindfulness session. Thus, the effect of the mindfulness training may be due to both the group sessions and the daily personal practice throughout the week. It would also be interesting to determine whether the results would differ if the control group were a daily active group, which in turn would allow future research on the effectiveness of mindfulness intervention programs [31].

\section{Conclusions}

Previous studies require further evidence of the effectiveness of mindfulness-based intervention programs on family caregivers' health $[14,31]$. This study shows evidence of the effects of mindfulness intervention programs with family caregivers on their health and well-being. These findings support the need for intervention policies that promote resources to improve well-being and reduce the burden on family caregivers.

Author Contributions: Conceptualization, C.F.-P., D.A., A.G.-F., J.G.A. and J.A.S.-M.; methodology, D.A. and C.F.-P.; software, D.A.; validation, C.F.-P., D.A., A.G.-F., J.G.A. and J.A.S.-M.; formal analysis, D.A. and C.F.-P.; investigation, A.G.-F. and J.G.A.; data curation, C.F.-P.; writing-original draft preparation, C.F.-P.; writing—review and editing, D.A. and C.F.-P.; supervision, J.A.S.-M. All authors have read and agreed to the published version of the manuscript.

Funding: This research received no external funding.

Institutional Review Board Statement: The study was conducted according to the guidelines of the Declaration of Helsinki and approved by the Institutional Review Board of the City Council of 
Olivares (Sevilla-Spain). Voluntary informed consent was requested. Participants were informed about the aims of the research and the right to withdraw without penalty if they wish. Questionnaires were registered with strict confidentiality. Date of approval: 1 September 2017.

Informed Consent Statement: Informed consent was obtained from all participants involved in the study.

Data Availability Statement: The data presented in this study are available on request from the corresponding author.

Acknowledgments: This study was conducted within the context of the City Council of Olivares (Sevilla-Spain).

Conflicts of Interest: The authors declare no conflict of interest.

\section{References}

1. Robine, J.M.; Cubaynes, S. Worldwide demography of centenarians. Mech. Ageing Dev. 2017, 165 Pt B, 59-67. [CrossRef] [PubMed]

2. The EU in the World-2020 Edition; Publications Office of the European Union: Luxembourg, 2020.

3. Cuéllar, A.F.; Sánchez, M.W. Programa de intervención para estimular la reserva cognitiva en el envejecimiento activo. Stud. Zamorensia 2020, 19, 91-101.

4. Serrano, J.P.; Latorre, J.M.; Gatz, M. Spain: Promoting the welfare of older adults in the context of population aging. Gerontologist 2014, 54, 733-740. [CrossRef]

5. Abellán García, A.; Aceituno Nieto, P.; Pérez Díaz, J.; Ramiro Fariñas, D.; Ayala García, A.; Pujol Rodríguez, R. Un Perfil de las Personas Mayores en España, 2019 Indicadores Estadísticos Básicos. Informes Envejecimiento en Red n ${ }^{\circ} 22$. Available online: http:/ / envejecimiento.csic.es/documentos/documentos/enred-indicadoresbasicos2019.pdf (accessed on 12 April 2021).

6. Gómez Redondo, R.; Fernández Carro, C.; Cámara Izquierdo, N. ¿Quién cuida a quién? La disponibilidad de cuidadores informales para personas mayores en España, 2018. Una aproximación demográfica basada en datos de encuesta. Inf. Envejec. En Red 2018, 20, 36.

7. Plöthner, M.; Schmidt, K.; De Jong, L.; Zeidler, J.; Damm, K. Needs and preferences of informal caregivers regarding outpatient care for the elderly: A systematic literature review. BMC Geriatr. 2019, 19, 82. [CrossRef] [PubMed]

8. Gilligan, C. New maps of development: New visions of maturity. Am. J. Orthopsychiatry 1982, 52, 199. [CrossRef]

9. McGuire, L.C.; Anderson, L.A.; Talley, R.C.; Crews, J.E. Supportive care needs of Americans: A major issue for women as both recipients and providers. J. Women's Health 2007, 16, 784-789. [CrossRef] [PubMed]

10. Setién Santamaría, M.L.; Acosta González, E. Managing the crisis in care and its relationship with the feminisation of migrations: A comparative analysis of the models in Spain and Chile. Alternativas 2010, 17, 63-81. [CrossRef]

11. Calvente, M.G.; del Río Lozano, M.; Marcos, J.M. Desigualdades de género en el deterioro de la salud como consecuencia del cuidado informal en España. Gac. Sanit. 2011, 25, 100-107. [CrossRef]

12. Pinquart, M.; Sörensen, S. Differences between caregivers and noncaregivers in psychological health and physical health: A meta-analysis. Psychol. Aging 2003, 18, 250. [CrossRef]

13. García-Alberca, J.M.; Lara, J.P.; Berthier, M.L. Anxiety and depression in caregivers are associated with patient and caregiver characteristics in Alzheimer's disease. Int. J. Psychiatry Med. 2011, 41, 57-69. [CrossRef] [PubMed]

14. Kiecolt-Glaser, J.K.; Preacher, K.J.; MacCallum, R.C.; Atkinson, C.; Malarkey, W.B.; Glaser, R. Chronic stress and age-related increases in the proinflammatory cytokine IL-6. Proc. Natl. Acad. Sci. USA 2003, 100, 9090-9095. [CrossRef] [PubMed]

15. Hiel, L.; Beenackers, M.A.; Renders, C.M.; Robroek, S.J.; Burdorf, A.; Croezen, S. Providing personal informal care to older European adults: Should we care about the caregivers' health? Prev. Med. 2015, 70, 64-68. [CrossRef]

16. Godfrey, J.R.; Warshaw, G.A. Toward optimal health: Considering the enhanced healthcare needs of women caregivers. J. Women's Health 2009, 18, 1739-1742. [CrossRef]

17. Mei, Y.; Lin, B.; Li, Y.; Ding, C.; Zhang, Z. Effects of modified 8-week reminiscence therapy on the older spouse caregivers of stroke survivors in Chinese communities: A randomized controlled trial. Int. J. Geriatr. Psychiatry 2018, 33, 633-641. [CrossRef]

18. Navarro-Abal, Y.; López-López, M.J.; Climent-Rodríguez, J.A.; Gómez-Salgado, J. Sobrecarga, empatía y resiliencia en cuidadores de personas dependientes. Gac. Sanit. 2019, 33, 268-271. [CrossRef]

19. Zarit, S.H.; Reever, K.E.; Bach-Peterson, J. Relatives of the impaired elderly: Correlates of feelings of burden. Gerontologist 1980, 20, 649-655. [CrossRef]

20. López Gil, M.; Orueta Sánchez, R.; Gómez-Caro, S.; Sánchez Oropesa, A.; Carmona de la Morena, J.; Moreno, A.; Javier, F. El rol de Cuidador de personas dependientes y sus repercusiones sobre su Calidad de Vida y su Salud. Rev. Clin. Med. Fam. 2009, 2, 332-339. [CrossRef]

21. Araújo, M.G.D.O.; Dutra, M.O.M.; Freitas, C.C.S.L.; Guedes, T.G.; Souza, F.S.D.; Baptista, R.S. Caring for the career: Quality of life and burden of female caregivers. Rev. Bras. Enferm. 2019, 72, 728-736. [CrossRef]

22. Dias, R.; Santos, R.L.; Sousa, M.F.B.d.; Nogueira, M.M.L.; Torres, B.; Belfort, T.; Dourado, M.C.N. Resilience of caregivers of people with dementia: A systematic review of biological and psychosocial determinants. Trends Psychiatry Psychother. 2015, 37, 12-19. [CrossRef] 
23. Palacio, C.; Krikorian, A.; Limonero, J.T. The influence of psychological factors on the burden of caregivers of patients with advanced cancer: Resiliency and caregiver burden. Palliat. Support. Care 2018, 16, 269-277. [CrossRef] [PubMed]

24. Limonero, J.T.; Fernández-Castro, J.; Soler-Oritja, J.; Álvarez-Moleiro, M. Emotional intelligence and recovering from induced negative emotional state. Front. Psychol. 2015, 6, 816. [CrossRef]

25. Iglesias, E.B. Resiliencia: Definición, características y utilidad del concepto. Rev. Psicopatol. Psicol. Clín. 2006, 11, 125-146.

26. Limonero, J.T.; Tomás-Sábado, J.; Fernández-Castro, J.; Gómez-Romero, M.J.; Ardilla-Herrero, A. Estrategias de afrontamiento resilientes y regulación emocional: Predictores de satisfacción con la vida. Behav. Psychol. 2012, 20, $183-196$.

27. Ong, H.L.; Vaingankar, J.A.; Abdin, E.; Sambasivam, R.; Fauziana, R.; Tan, M.E.; Subramaniam, M. Resilience and burden in caregivers of older adults: Moderating and mediating effects of perceived social support. BMC Psychiatry 2018, 18, 27. [CrossRef]

28. Li, Y.; Wang, K.; Yin, Y.; Li, Y.; Li, S. Relationships between family resilience, breast cancer survivors' individual resilience, and caregiver burden: A cross-sectional study. Int. J. Nurs. Stud. 2018, 88, 79-84. [CrossRef] [PubMed]

29. Tahsin, F.; Stanyon, W.; Sun, W.; Gamble, B. A single mindfulness session with informal caregivers of seniors living with dementia: A pilot qualitative descriptive study. Aging Clin. Exp. Res. 2021, 33, 391-397. [CrossRef]

30. Kubo, A.; Kurtovich, E.; McGinnis, M.; Aghaee, S.; Altschuler, A.; Quesenberry, C., Jr.; Avins, A. Pilot pragmatic randomized trial of mHealth mindfulness-based intervention for advanced cancer patients and their informal caregivers. Psychoncology 2020, 1-11. [CrossRef]

31. Collins, R.N.; Kishita, N. The effectiveness of mindfulness-and acceptance-based interventions for informal caregivers of people with dementia: A meta-analysis. Gerontologist 2019, 59, e363-e379. [CrossRef]

32. Diener, E.D.; Emmons, R.A.; Larsen, R.J.; Griffin, S. The satisfaction with life scale. J. Pers. Assess. 1985, 49, 71-75. [CrossRef]

33. Goldberg, D.P. The Detection of Psychiatric Illness by Questionnaire; Maudsley Monograph: No 21; Oxford University Press: London, UK, 1972.

34. Connor, K.M.; Davidson, J.R. Development of a new resilience scale: The Connor-Davidson resilience scale (CD-RISC). Depress. Anxiety 2003, 18, 76-82. [CrossRef]

35. Zarit, S.H.; Zarit, J.M. Families under stress: Interventions for caregivers of senile dementia patients. Group Dyn. 1982, $19,461$. [CrossRef]

36. Kocovski, N.L.; Fleming, J.E.; Rector, N.A. Mindfulness and acceptance-based group therapy for social anxiety disorder: An open trial. Cogn. Behav. Pract. 2009, 16, 276-289. [CrossRef]

37. Vøllestad, J. Mindfulness-and acceptance-based interventions in the treatment of anxiety disorders. In Mindfulness and BuddhistDerived Approaches in Mental Health and Addiction; Springer: Cham, Switzerland, 2016; pp. 97-137.

38. Haugmark, T.; Hagen, K.B.; Smedslund, G.; Zangi, H.A. Mindfulness-and acceptance-based interventions for patients with fibromyalgia-A systematic review and meta-analyses. PLoS ONE 2019, 14, e0221897. [CrossRef] [PubMed]

39. Muthén, B.; Muthén, B.O. Statistical Analysis with Latent Variables; Wiley: New York, NY, USA, 2009.

40. Hou, R.; Moss-Morris, R.; Risdale, A.; Lynch, J.; Jeevaratnam, P.; Bradley, B.P.; Mogg, K. Attention processes in chronic fatigue syndrome: Attentional bias for health-related threat and the role of attentional control. Behav. Res. Ther. 2014, 52, 9-16. [CrossRef]

41. Bustillo, M.; Gómez-Gutiérrez, M.; Guillén, A.I. Los cuidadores informales de personas mayores dependientes: Una revisión de las intervenciones psicológicas de los últimos diez años. Clin. Salud 2018, 29, 89-100. [CrossRef]

42. Jaffray, L.; Bridgman, H.; Stephens, M.; Skinner, T. Evaluating the effects of mindfulness-based interventions for informal palliative caregivers: A systematic literature review. Palliat. Med. 2016, 30, 117-131. [CrossRef]

43. Loi, S.M.; Dow, B.; Ames, D.; Moore, K.; Hill, K.; Russell, M.; Lautenschlager, N. Physical activity in caregivers: What are the psychological benefits? Arch. Gerontol. Geriatr. 2014, 59, 204-210. [CrossRef]

44. Moola, F.; Fusco, C.; Kirsh, J.A. The Perceptions of Caregivers toward Physical Activity and Health in Youth with Congenital Heart Disease. Qual. Health Res. 2011, 21, 278-291. [CrossRef] 